\title{
THE NSW REFUGEE SCREENING PROGRAM
}

Mitchell Smith, Medical Officer

Greg Stewart, Director

SWS Public Health Unit

Sheila Simpson, Clinical Nurse Consultant

Liverpool Chest Clinic

$T^{\mathrm{h}}$ his report describes the activities and results of the Refugee Screening Program in the first 12 months of operation since its reorganisation and relocation to Liverpool.

Health screening of newly arrived South East Asian refugees migrating to NSW began in 1977 and was extended to include refugees from Central and South America in 1984. An evaluation of this service in 1985 led to some changes in the way screening, then based at Lidcombe Hospital, was conducted - for example, routine anti-malarial therapy was discontinued ${ }^{1}$. A further Health Department review in 1991 supported many of the original recommendations that had not been implemented and made several new ones ${ }^{2}$. As a result, the program was relocated to Liverpool Chest Clinic in April 1993. Various changes to the protocol have been made and a database has been set up to record results of screening.

\section{SCREENING PROTOCOL}

The current screening protocol consists of:

$\square$

brief medical history and physical examination (both focusing on communicable diseases);

tuberculin test (unless prior tuberculosis or under three months old); chest x-ray (15 years and over ${ }^{3}$ );

venepuncture for syphilis and hepatitis B (15 years and over); and

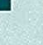
immunisation as required (as per National Health and Medical Research Council guidelines).

Certain migrants, such as those with a history of tuberculosis (TB), have signed a conditional entry permit called a health undertaking (known as a TBU). People on TBUs undergo $\mathrm{x}$-ray at a later time at their nearest Chest Clinic, when pre-migration films are available for comparison.

Tuberculin tests are read after 72 hours at the nearest Chest Clinic. Results are explained and information about

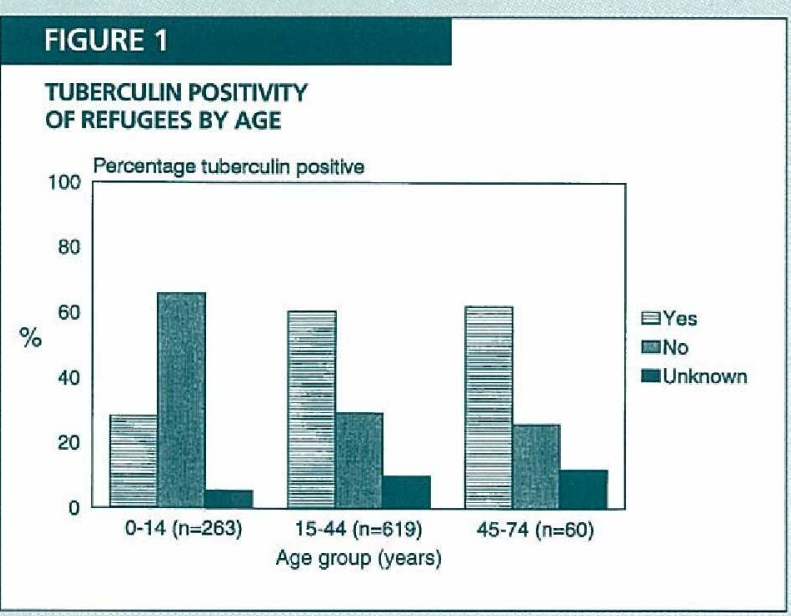

\begin{tabular}{|c|c|c|}
\hline \multicolumn{3}{|c|}{$\begin{array}{l}\text { REASONS FOR REFUGEES SIGNING } \\
\text { HEALTH UNDERTAKINGS }\end{array}$} \\
\hline TBU reason & No. & $\%$ \\
\hline $\begin{array}{l}\text { TB in past } \\
\text { Contact of TB } \\
\text { Abnormal CXR } \\
\text { Poor quality CXR } \\
\text { Unknown }\end{array}$ & $\begin{array}{r}30 \\
19 \\
25 \\
3 \\
18\end{array}$ & $\begin{array}{r}(32) \\
(20) \\
(26) \\
(3) \\
(19)\end{array}$ \\
\hline Total & 95 & $(100)$ \\
\hline
\end{tabular}

- = chest $\mathrm{x}$-ray

the health care system and available services is provided. A NSW Personal Health Record is given to children aged under five years, while others receive a card listing test results and vaccinations given.

\section{METHODS}

Since April 1993 routine data collection, recorded using Epi Info, has provided a reference source about individuals and a means of measuring disease detection rates ${ }^{2.4}$. For each person screened, demographic details, test results and vaccines given are recorded. Clinical diagnoses for those referred for abnormal chest x-rays or positive syphilis serology are sought from the appropriate clinic. Data about diseases with less public health significance (e.g. scabies, otitis) are not collated.

Tuberculin positivity was defined as induration of $10 \mathrm{~mm}$ or greater for children under 15 years, regardless of BCG status; for those 15 years and over, $10 \mathrm{~mm}$ or greater if no $\mathrm{BCG}$ scar, and $15 \mathrm{~mm}$ or greater for those with a BCG scar ${ }^{3}$.

\section{RESULTS}

\section{Attendance}

In the 12-month period from April 1993, 1,006 people were eligible for screening, of whom 989 ( 98.3 per cent) attended screening. Three of the 17 refugees who did not attend had signed a TBU pre-migration. Of the 922 people who had tuberculin tests, 839 (91 per cent) had a result recorded.

\section{Demographic details}

Ninety-five per cent of refugees screened in this period were Vietnamese, the majority of whom came from camps in Indonesia or the Philippines. The remainder of refugees seen originated from Cambodia, Somalia and El Salvador.

More than 85 per cent of those seen were under 40 years of age. The male:female ratio was 1.1 .

\section{Disease detection}

i) Tuberculosis

Ninety-five people seen (almost 10 per cent) had signed health undertakings before embarkation. Reasons for these are shown in Table 4 . Chest x-ray abnormalities, most of which were detected by the Commonwealth's Migrant Medical Clearances Unit, were generally minor in nature. Information about 18 TBUs was unavailable at the time of screening.

Screening chest $\mathrm{x}$-rays are taken using small ( $100 \mathrm{~mm}$ size) films. There were 639 such x-rays taken; 23 (4 per cent) were reported as abnormal. Follow-up of these abnormalities revealed that nine of them ( 39 per cent) were false positives, the large film being normal. Two abnormalities were non-tuberculous (a bony mass and a vascular abnormality), and the remainder were being 


\begin{tabular}{|c|c|c|}
\hline \multicolumn{3}{|c|}{$\begin{array}{l}\text { TABLE } 5 \\
\text { CLINICAL DIAGNOSES FOR REFUGEES } \\
\text { WITH POSITIVE TPHA }\end{array}$} \\
\hline Syphilis & No. & $\%$ \\
\hline Inactive & 11 & (26) \\
\hline Latent & 19 & (45) \\
\hline Partly treated & 7 & (17) \\
\hline False positive & 2 & (5) \\
\hline Unknown & 3 & (7) \\
\hline Total & 42 & $(100)$ \\
\hline
\end{tabular}

monitored with Chest Clinic follow-up. No cases of active pulmonary tuberculosis were found among those $\mathrm{x}$-rayed. Outcomes for five people with an abnormal small film were unknown.

Overall, 93 per cent of refugees screened had a tuberculin test. Results are shown in Figure 1. Missing data (9 per cent of tests done) reflect either failures to return for readings, or results not forwarded from other Chest Clinics.

Of 15 tuberculin-positive children ( 0 -14 years) for whom follow-up is known, preventive therapy was judged necessary for only one child.

\section{ii) Syphilis}

Forty-two people aged 15 years and over ( 5.9 per cent) had a reactive Treponema Pallidum Haemagglutination (TPHA) test. The prevalence was higher in males ( 8.1 per cent) than in females ( 3.3 per cent).

In contrast, the Reactive Plasma Reagin (RPR) test is used for overseas screening of intending refugee migrants. Only 8 of the above 42 people ( 20 per cent) had a positive RPR test overseas.

The 42 people with a reactive TPHA test were followed up at Sexual Health Clinics (Table 5). Twenty-six of these (62 per cent) received daily penicillin for 15 days as treatment for presumptive late latent syphilis. Seven of these cases had been detected and treated in the camps overseas, where a weekly regime of penicillin therapy is used. These individuals were treated again to ensure adequate clearance of infection.

\section{iii) Hepatitis $B$}

Routine testing for hepatitis B began in January 1994. For those seen during the four months from January to April 1994 ( $n=184$ ), the overall prevalence of surface antigen carriage was 15 per cent. Half the carriers were e antigen positive, indicating greater infectivity.

Carriers ranged in age from 15 to 46 years, and 20 of 27 ( 74 per cent) were male. The stored sera from family members of carriers are tested for hepatitis B surface antibodies. There were 23 such contacts aged 15 years and over, of whom 10 ( 43 per cent) were non-immune to hepatitis B.

\section{iv) Immunisation status}

Vaccination records were available for 83 per cent of refugees seen. Immunisation status of children with records is shown in Table 6.

Hepatitis B vaccination status was not included when measuring completeness of immunisations. However, it was found that 57 of the 79 under-fives ( 72 per cent)

\begin{tabular}{|c|c|c|c|c|}
\hline \multicolumn{5}{|c|}{$\begin{array}{l}\text { IMMUNISATION STATUS OF } \\
\text { REFUGEE CHILDREN }\end{array}$} \\
\hline \multicolumn{5}{|c|}{ Fully immunised for age } \\
\hline Age group & $\begin{array}{l}\text { Yes } \\
(\%)\end{array}$ & $\begin{array}{l}\text { No. } \\
(\%)\end{array}$ & $\begin{array}{l}\text { Unk* } \\
(\%)\end{array}$ & $\begin{array}{r}\text { Total } \\
(\%)\end{array}$ \\
\hline $0-4$ & $\begin{array}{c}66 \\
(84)\end{array}$ & $\begin{array}{c}12 \\
(15)\end{array}$ & $\begin{array}{c}1 \\
\text { (1) }\end{array}$ & $\begin{array}{r}79 \\
(100)\end{array}$ \\
\hline $5-14$ & $\begin{array}{l}109 \\
(77)\end{array}$ & $\begin{array}{r}26 \\
(18)\end{array}$ & $\begin{array}{c}6 \\
(4)\end{array}$ & $\begin{array}{c}141 \\
(100)\end{array}$ \\
\hline Total & $\begin{array}{l}175 \\
(79)\end{array}$ & $\begin{array}{c}38 \\
(17)\end{array}$ & $\begin{array}{c}7 \\
\text { (3) }\end{array}$ & $\begin{array}{c}220 \\
(100)\end{array}$ \\
\hline
\end{tabular}

* missing data

\begin{tabular}{|c|c|c|c|}
\hline \multicolumn{4}{|l|}{ TABLE 7} \\
\hline \multicolumn{4}{|c|}{ SUMMARY OF DISEASES DETECTED } \\
\hline Disease & $\begin{array}{r}\text { No. } \\
\text { tested }\end{array}$ & $\begin{array}{r}\text { No. } \\
\text { positive }\end{array}$ & $\%$ \\
\hline Active pulmonary TB & 639 & 0 & (0) \\
\hline Tuberculin positivity & 922 & 477 & (51.7) \\
\hline Preventive TB therapy & & & \\
\hline in child $<15$ years & 253 & 1 & $(0.4)$ \\
\hline Latent syphilis & 715 & 26 & (3.6) \\
\hline Hepatitis B carriage & 184 & 27 & (14.7) \\
\hline
\end{tabular}

with documentation had received hepatitis $B$ vaccine. In contrast, only 24 of 141 children aged 5-14 years (17 per cent) had received this.

There were 296 women of child-bearing age ( $15-40$ years). Rubella vaccine was required by 131 of these (44 per cent).

v) Leprosy

No confirmed cases were detected.

\section{DISCUSSION}

The attendance rate for screening was very high during these 12 months, despite initial concerns that the program's move to Liverpool may affect this. In addition, more than 90 per cent of those given a tuberculin test had their result read; this was a reasonable follow-up rate.

There is often a delay of 6-12 months from the pre-migration chest $x$-ray until the refugee's departure for Australia.

Despite this, no new cases of active TB were detected here in screened refugees. In addition, a high false positive rate for miniature $x$-rays was seen. An evaluation should be made of routine chest $\mathrm{x}$-ray use at the initial visit versus $\mathrm{x}$-ray according to tuberculin test result (as occurs at the six-month refugee follow-up).

Overall tuberculin positivity was just over 50 per cent, and tended to increase with age. Children with a positive tuberculin test are generally recalled for assessment by a physician. Available data show that most were not given preventive therapy, as has been found in other settings ${ }^{5,6}$. 


\section{INFECTIOUS DISEASES}

\author{
MEASLES EPIDEMIC, SOUTH COAST NSW \\ Greg Sam and Paul Van Buynder \\ South East NSW Public Health Unit \\ Shanti Raman \\ National Centre for Epidemiology and Population Health \\ John Skinner \\ North Sydney Public Health Unit
}

Between August 20 and November 8, 1994, 214 measles notifications were received by the South Eastern Public Health Unit from the South Coast District of NSW.

The epidemic was centred in the Bega Valley area, with

43 per cent of known cases occurring in students at Bega

High School. The outbreak peaked during the week

beginning September 25, which was the first week of the Term 3 school holidays (Figure 2).

Measles cases were defined as people having an illness characterised by:

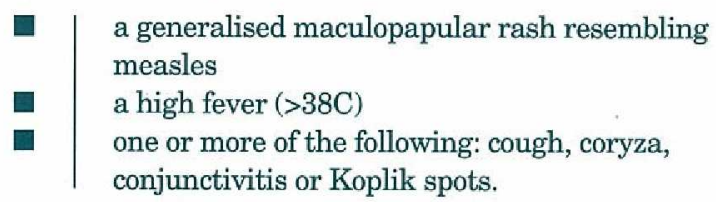

\section{NSW refugee screening}

\section{Continued from page 135}

Improved data collection on the proportion of tuberculinpositive children screened who receive preventive therapy is recommended.

The RPR screening test for syphilis used pre-migration has been shown here to miss 80 per cent of refugees with evidence of past treponemal disease, as previously reported ${ }^{2}$ The TPHA test is more sensitive in this situation as it usually remains reactive lifelong. Some positive TPHA results among refugees may be due to other treponemal diseases such as yaws or pinta, which are indistinguishable from syphilis on serological grounds. However, those who do have latent syphilis are at risk of progression to tertiary disease. The detection of these cases, with assessment for therapy, is therefore important in personal and public health terms.

Hepatitis B tests are not performed pre-migration. Because serum is collected for syphilis testing from those 15 years and older, it was decided to limit hepatitis B tests to the same age group. The prevalence of the carrier state is, as expected, high. Testing allows appropriate advice to be given to carriers and their families; further serological testing of adult contacts determines their need for vaccination. Catch-up immunisation against hepatitis B is offered to all children under 15 years old not previously vaccinated. This is done without prior serological testing, based on cost calculations and the known safety of the vaccine?

Immunisation status is well documented for arriving refugees, and coverage for children is high. The screening visit is an excellent opportunity for catch-up vaccination in adults and children. For example, HIB vaccine is not given in the camps, and most adults have never received Sabin.

\section{Case notifications}

On September 22, two days before the end of the school term, a South Coast general practitioner notified the South Eastern NSW PHU of two cases of clinically diagnosed measles in Bega High School students. Follow-up with the school identified a high level of measles-related absenteeism in the preceding two weeks.

Potential sources for further case identification were contacted throughout the area, including hospitals, GPs, schools, and preschool and child care centres. The need for prompt notification of cases was stressed.

A high attack rate among high school-aged children was identified and questionnaires were distributed to the two local high schools to ascertain the degree of under-reporting of cases.

\section{Serological confirmation was obtained from 35 cases.}

\section{Immunisation campaign}

The need for measles vaccination for all unimmunised children as well as a recommendation for a booster dose for children aged 10-17 years who had been previously vaccinated was highlighted in school letters and through the local media.
The current screening program is routinely offered to refugees from South East Asia and Central and South America only. While small numbers from other areas are starting to be seen, routine screening of refugees from Africa, Eastern Europe and the Middle East should be introduced, based on known rates of tuberculosis in the country of origin ${ }^{2}$.

In summary, most of the major recommendations of the 1991 review of refugee screening ${ }^{2}$ have been implemented, including relocation to a Chest Clinic, increased emphasis on diseases of public health significance, introduction of hepatitis B testing and upgraded data collection. In addition, the program has been streamlined: those with personal health problems are referred to general practitioners as much as possible; there is rapid feedback of results; and routine treatment for intestinal parasites is no longer given, as nearly all South East Asian refugees have received treatment with pyrantel just before their departure for Australia.

1. Reid J, Goldstein GB, Keo L. An evaluation of refugee medical screening in NSW. November 1985. Report to the NSW Department of Health, Western Metropolitan Region. NSW Health Department, Sydney, 1985

2. Bek M, Levy M. A review of the NSW refugee medical screening program. June 1991. NSW Health Department, State Health Publication No. (EHSEB) 92-12, Sydney, 1991.

3. Westley-Wise V, Levy M, Lonie C, McAnulty J, Winks M, Stewart G. Controlling Tuberculosis in New South Wales. March 1993. NSW Health Department, Sydney, 1993.

4. McAnulty J, Levy M, Rubin G. Eliminating tuberculosis:

Where is the strategy? NSW Public Health Bulletin 1992; 3(4):39-40. 5 . Westley-Wise V, Levy M, Winks M. Review of tuberculosis services in New South Wales. December 1992. NSW Health Department, Sydney, 1992.

6. Alperstein G, Fett MJ, Reznik R, Thomas M, Senthil M. The prevalence of tuberculosis infection among Year 8 schoolchildren in inner Sydney in 1992. Med J Aust 1994; 160:197-201.

7. US Department of Health and Human Services. Protection against viral hepatitis. Recommendations of the Immunization Practices 